\title{
Adrenomedullin Is Highly Expressed in Blood Monocytes Associated with Acute Kawasaki Disease: A Microarray Gene Expression Study
}

\author{
ICHIRO NOMURA, JUN ABE, SEIJI NOMA, HIROHISA SAITO, BIFENG GAO, \\ GARY WHEELER, AND DONALD Y.M. LEUNG \\ Department of Pediatrics [I.N., D.Y.M.L.], National Jewish Medical and Research Center, Denver, CO, 80206; \\ Department of Allergy and Immunology [I.N.], National Center for Child Health and Development, Tokyo \\ 154-8567, Japan; Department of Allergy and Immunology [J.A., H.S.], National Research Institute for Child \\ Health and Development, Tokyo 154-8567, Japan; Hachioji Metropolitan Children's Hospital [S.N.], Tokyo, \\ Japan; University of Colorado Health Sciences Center [B.G.], School of Medicine, Microarray Core \\ Laboratory, Denver, CO 80262; and Department of Pediatrics [G.W.], Children's Hospital Little Rock, AR \\ 72205
}

\section{ABSTRACT}

Kawasaki disease (KD) is an acute inflammatory disorder of children frequently associated with the development of coronary artery abnormalities. Although a great deal is known about inflammatory and immune responses in acute $\mathrm{KD}$, the mechanisms linking the immune response to vascular changes are not known. To gain further insight into this process, we performed a microarray gene expression analysis on RNA isolated from the peripheral blood mononuclear cells of four patients with KD during both their acute and convalescent phases. Forty-seven genes of 7129 genes examined showed an increased expression in three or all four patients in the acute compared with the convalescent phase of KD. Fourteen of these genes were significantly $(p<0.05)$ up-regulated, including several inflammatory response genes (e.g. S-100 A9 protein) and also anti-inflammatory genes (e.g. TSG-6). Of greatest interest, the adrenomedullin (ADM) gene, known to be associated with coronary artery vasodilation, was up-regulated in the acute phase of $\mathrm{KD}(p=$ 0.024). Up-regulation of $\mathrm{ADM}$ in the acute phase of $\mathrm{KD}$ was confirmed in peripheral blood mononuclear cells of 11 additional $\mathrm{KD}$ patients by reverse transcriptase-PCR $(p<0.01)$. Isolated blood monocytes but not lymphocytes were demonstrated by real- time PCR to have increased ADM mRNA ( $p=0.01)$. Plasma ADM protein level in 32 additional $\mathrm{KD}$ patients was also confirmed to be higher in acute $\mathrm{KD}$ compared with convalescent $\mathrm{KD}(p<0.032)$. It is interesting that from microarray results, other molecules known to be associated with coronary dilation, including nitric oxide, prostacyclin, acetylcholine, bradykinin, substance $\mathrm{P}$, and serotonin, were not elevated in acute KD. Our current study suggests that ADMexpressing monocytes that infiltrate the coronary vascular wall may be the cause of coronary dilation in the acute phase of KD. (Pediatr Res 57: 49-55, 2005)
ADM, adrenomedullin
Abbreviations
EIA, enzyme immunoassay
GAPDH, glyceraldehyde-3-phosphate dehydrogenase
IVIG, intravenous immunoglobulin
KD, Kawasaki disease
PBMC, peripheral blood mononuclear cell
RT-PCR, reverse transcriptase-PCR

Kawasaki disease (KD) is an acute vasculitis that affects mainly infants and young children (1). Ten to $15 \%$ of patients with untreated KD develop coronary arterial lesions, and a

Received December 23, 2003; accepted July 19, 2004.

Correspondence: Donald YM Leung, M.D., Ph.D., National Jewish Medical and Research Center, Department of Pediatrics, Room K926I, 1400 Jackson Street, Denver, CO 80206; e-mail: leungd@njc.org

This research was supported in part by National Institutes of Health grants HL36577, AR41256, and HL37260; the Ann and Louis Rudolph Kawasaki Disease Research Fund; and the Edelstein Family Chair in Pediatric Allergy and Immunology, the University of Colorado Cancer Center; and a grant from Child Health and Development from the Ministry of Health, Labor and Welfare, Japan.

DOI: 10.1203/01.PDR.0000147745.52711.DD greater proportion of patients develop coronary arterial dilation (ectasia) (2,3). Many studies have demonstrated that the acute phase of $\mathrm{KD}$ is associated with activation of $\mathrm{T}$ cells and monocyte/macrophages (4-6). However, the mechanisms linking the systemic immune response to vascular abnormalities are unknown.

Using new approaches such as the DNA microarray method (7), it is possible to examine thousands of genes, which may be up- or down-regulated during acute compared with convalescent $\mathrm{KD}$, for identification of novel disease processes (mechanisms). Because autopsy cases have demonstrated that the infiltration of macrophages and $\mathrm{T}$ cells are prominent in the 
coronary artery and other vascular lesions of patients with $\mathrm{KD}$ (8), one can presume that the up-regulated genes in the mononuclear cells found at the site of coronary artery abnormalities can be detected in the gene-expression patterns of peripheral blood mononuclear cells (PBMCs). The current study used the Affymetrix GeneChip technology to identify potential candidate genes that might link the systemic immune response to development of vasculitis and coronary artery disease by examining the gene-expression patterns of PBMCs from patients with acute and convalescent KD.

\section{METHODS}

Study patients. For the microarray gene expression study, PBMCs were obtained from four patients who had KD, one girl and three boys, and were treated in Hachioji Metropolitan Children's Hospital (Tokyo, Japan; see Table 1). Because patients with KD are usually infants and young children, insufficient paired acute and convalescent blood could be obtained from other patients with KD to use in the microarray studies. Blood samples were taken during the acute and convalescent phases in each patient. Immediately after blood sampling was done, i.v. immunoglobulin (IVIG) was administered to the patients. No one showed coronary dilation by echocardiography. This might be because IVIG therapy was performed in the very early stage of the KD and vasculitis was treated before the formation of coronary dilations. All four patients received oral aspirin treatment. Patients 1,2, and 4 were treated with $5 \mathrm{~d}$ of sequential IVIG $400 \mathrm{mg} \cdot \mathrm{kg}^{-1} \cdot \mathrm{d}^{-1}$. Patient 3 was treated with $7 \mathrm{~d}$ of sequential IVIG $400 \mathrm{mg} \cdot \mathrm{kg}^{-1} \cdot \mathrm{d}^{-1}$.

For the reverse transcriptase-PCR (RT-PCR) study, 11 patients who had $\mathrm{KD}$ ( 4 girls and 7 boys; mean age $26 \mathrm{mo} \pm 20 \mathrm{SD}$ ) and also were treated in Hachioji Metropolitan Children's Hospital were enrolled. Blood samples were taken during the acute $(5.0 \mathrm{~d} \pm 1.4 \mathrm{SD})$, subacute $(10 \mathrm{~d} \pm 1.4 \mathrm{SD})$, and convalescent $(104.7 \mathrm{~d} \pm 34.4 \mathrm{SD})$ phases in each patient. The mean white blood cell count in the acute phase was $13,300 / \mathrm{mm}^{3} \pm 2,900$. The mean value of C-reactive protein in the acute phase was $6.6 \mathrm{mg} / \mathrm{dL} \pm 2.7$.

For plasma adrenomedullin (ADM) concentration, another 32 patients who were treated in Hachioji Metropolitan Children's Hospital (Japan) were enrolled. All patients fulfilled the diagnostic criteria for KD as defined by the American Heart Association Committee on Rheumatic Fever, Endocarditis, and $\mathrm{KD}(9)$.

Two-dimensional echocardiography was performed before treatment with i.v. gamma globulin and during the convalescent phase. A coronary artery with a diameter of $3 \mathrm{~mm}$ or more ( $4 \mathrm{~mm}$ if the patient was older than $5 \mathrm{y}$ ) was defined as abnormal. Parental informed consent was obtained for each child enrolled in this study. This study was approved by the Research Ethics Committee of the Hachioji Metropolitan Children's Hospital (Japan).

Affymetrix GeneChip protocol. Five-microgram samples of total RNA isolated from PBMCs were individually converted to double-stranded cDNA (ds-cDNA) using the Superscript Choice system (Life Technologies, Rockville, MD). An oligo-dT primer that contained a T7 RNA polymerase promoter (Promega Corp., Madison, WI) was used. After second-strand synthesis, the reaction mixture was extracted with phenol-chloroform-isoamyl alcohol, and the ds-cDNA was recovered by ethanol precipitation. In vitro transcription and biotin-labeling were then performed with an RNA transcript labeling kit (Enzo Biochem, Inc., New York, NY). A ds-cDNA template was transcribed in the presence of a mixture of unlabeled ATP, CTP, GTP, UTP, and biotin-labeled
CTP and UTP (Enzo Biochem, Inc.). Synthesized cRNA was fragmented in a fragmentation buffer at $94^{\circ} \mathrm{C}$ for $35 \mathrm{~min}$. Samples were then used to prepare a hybridization solution that contained $100 \mathrm{mM}$ of 2-[N-Morpholino] ethenesulfonic acid, $1 \mathrm{M}$ of $\mathrm{NaCl}$, and $20 \mathrm{mM}$ of EDTA in the presence of $0.01 \%$ Tween 20. Each of the four acute samples and four convalescent samples was loaded individually into respective (total eight) human FL GeneChip probe arrays that contained 7129 gene probes (Affymetrix Inc., Santa Clara, CA) and hybridized at $45^{\circ} \mathrm{C}$ for $16 \mathrm{~h}$. After washing and staining with streptavidin-phycoerythrin, the probe arrays were scanned using a Gene-array scanner (Hewlett Packard, Palo Alto, CA).

The data were analyzed using MicroArray Suite Version 4.0 software (Affymetrix Inc.). Detailed protocols for data analysis of Affymetrix microarrays and extensive documentation of the sensitivity and quantitative aspects of the method have been described $(10,11)$ (Affymetrix Microarray Suite, version 4.0, User's guide). Genes were grouped as "increase" or "decrease" in the acute phase in comparison with the convalescent phase of each patient. For the normalization of fluorescence intensity, raw data from array scans were averaged across all gene probes on each array, and a scaling factor was applied to bring the average intensity for all probes on the array to a user preset level (2500). This allows any sample to be normalized for comparison with any other comparable sample, e.g. acute phase versus convalescent phase. We used a paired, two-tailed $t$ test to assess whether gene expression differences were significant $(p<0.05)$.

Monocyte/lymphocyte isolation procedures. Peripheral blood monocytes and T cells were separated using a RosetteSep Monocyte or T cell Enrichment Cocktail (StemCell Technologies Inc., Vancouver, British Columbia, Canada) according to the manufacturer's recommendations (12). Briefly, $2 \mathrm{~mL}$ of heparinized blood was mixed with $20 \mu \mathrm{L}$ of $100 \mathrm{mM}$ of EDTA and $100 \mu \mathrm{L}$ of RosetteSep cocktail that contained antibodies to human CD2, CD3, CD8, CD19, CD56, and CD66b for monocyte, or human CD16, CD19, CD36, and $\mathrm{CD} 56$ for $\mathrm{T}$ cell. After incubation for $20 \mathrm{~min}$ at room temperature, the sample was diluted with an equal volume of PBS that contained $2 \%$ fetal bovine serum and $1 \mathrm{mM}$ of EDTA and layered on top of $4 \mathrm{~mL}$ of Ficoll-Paque (Amersham Biosciences, Uppsala, Sweden). The tubes were then centrifuged at $2000 \mathrm{rpm}$ at room temperature for $20 \mathrm{~min}$. The interface between plasma and FicollPaque was collected, washed, and stored in liquid nitrogen until RNA extraction. The CD14(+) monocytes and CD3(+) T cells typically represented $\sim 75$ and $93.5 \%$, respectively, of the total cells by flow cytometry analysis after this enrichment procedure.

Semiquantitative RT-PCR for ADM. Two micrograms of total RNA was used for the synthesis of first-strand cDNA, and the expression of ADM and glyceraldehyde-3-phosphate dehydrogenase (GAPDH) was examined using specific primer pairs. The sequences of the primers were 5'-TTCGGAGTTTTGCCATTGCCAG-3' (sense) and 5'-TCCTTGTCCTTATCTGTGAACTGGT-3' (antisense) for ADM and 5'-CCAGCCGAGCCACATCGCTCT-3' (sense) and 5'-GTTGGCAGTGGGGACACGGAA-3' (antisense) for GAPDH. PCR was carried out in a $50-\mu \mathrm{L}$ reaction mixture that contained 1.25 units of HotStaTaq DNA polymerase (Qiagen), $1.5 \mathrm{mM}$ of $\mathrm{MgCl}_{2}, 0.2 \mu \mathrm{M}$ of each $\mathrm{dNTP}$, and $0.3 \mu \mathrm{M}$ of primer pairs. One microliter of each cDNA was subjected to amplification with 32 cycles of $1 \mathrm{~min}$ at $95^{\circ} \mathrm{C}, 1 \mathrm{~min}$ at $57^{\circ} \mathrm{C}$, and $1 \mathrm{~min}$ at $72^{\circ} \mathrm{C}$ for $\mathrm{ADM}$ and 26 cycles of $1 \mathrm{~min}$ at $95^{\circ} \mathrm{C}, 1 \mathrm{~min}$ at $60^{\circ} \mathrm{C}$, and $1 \mathrm{~min}$ at $72^{\circ} \mathrm{C}$ for GAPDH. For quantification of amplified products, ${ }^{33} \mathrm{P}$ end-labeled $3^{\prime}$ primers were added to the reactions. The amplified products were separated on $2 \%$ agarose gels, dried, and analyzed with a BAS2000 Bio Image Analyzer (Fujix Film Co., Tokyo, Japan). The percentage of ADM to GAPDH mRNA was calculated after measurement of incorporated radioactivities.

Table 1. Clinical data of four KD patients examined with GeneChip microarray

\begin{tabular}{|c|c|c|c|c|c|c|c|}
\hline \multirow[b]{2}{*}{ Patient } & \multirow[b]{2}{*}{ Gender } & \multirow{2}{*}{$\begin{array}{l}\text { Age } \\
(\mathrm{mo})\end{array}$} & \multirow{2}{*}{$\begin{array}{c}\text { WBC } \\
\left(\text { cells } / \mu \mathrm{m}^{3}\right)\end{array}$} & \multirow{2}{*}{$\begin{array}{c}\text { CRP } \\
(\mathrm{mg} / \mathrm{dL})\end{array}$} & \multirow[b]{2}{*}{ Coronary dilation } & \multicolumn{2}{|c|}{ Disease day* } \\
\hline & & & & & & Acute & Convalescent \\
\hline 1 & $\mathrm{~F}$ & 4 & 12,500 & 10.0 & - & 4 & 13 \\
\hline 3 & M & 26 & 23,300 & 12.3 & - & 3 & 20 \\
\hline 4 & M & 30 & 14,900 & 8.0 & - & 5 & 111 \\
\hline
\end{tabular}

WBC, white blood cell count (normal $<9000$ cells $/ \mu \mathrm{m}^{3}$ ); CRP, C-reactive protein (normal $<0.3 \mathrm{mg} / \mathrm{dL}$ ).

* The disease day blood was obtained. 
Table 2. Results of GeneChip microarray: genes with increased call in at least three patients with acute KD

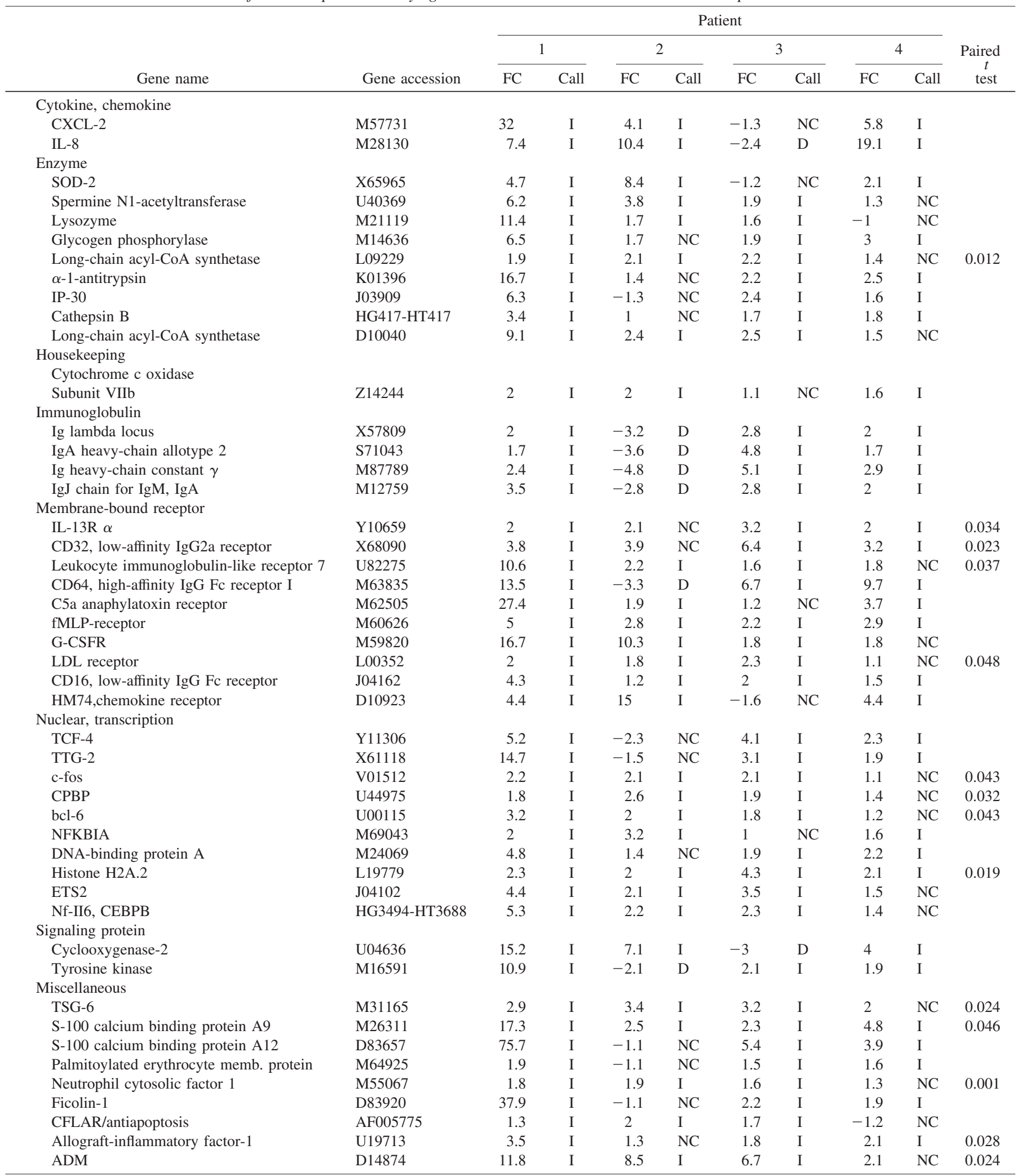

FC, fold change in acute-phase KD compared with convalescent phase; I, increase (increased gene in acute phase compared with convalescent phase); NC, not changed; D, decreased gene.

Real-time PCR for ADM. Total RNA was isolated from the monocyteenriched versus lymphocyte-enriched PBMCs using ISOGEN (Wako Pure Chemical Industries, Osaka, Japan) according to the manufacturer's instructions and reverse-transcribed to cDNA. The expression of ADM and GAPDH was determined by a real-time PCR using the ABI 7700 sequence detector system (PE Applied Biosystems, Foster City, CA). The primers and probes for GAPDH and ADM were purchased from PE Applied Biosystems (Assays-onDemand Gene Expression Products). The assay ID (catalog number) of GAPDH was Hs99999905_m1, and the assay ID of ADM was Hs00181605 _m1. PCR was carried out in a $25-\mu \mathrm{L}$ reaction mixture that contained $12.5 \mu \mathrm{L}$ 
of TaqMan Universal PCR Master Mix (PE Applied Biosystems), $1.25 \mu \mathrm{L}$ of $20 \times$ Assays-on-Demand Gene Expression Assay Mixture (PE Applied Biosystems), and $11.25 \mu \mathrm{L}$ of cDNA diluted in RNase-free $\mathrm{H}_{2} \mathrm{O}$. Samples were preincubated for $10 \mathrm{~min}$ at $95^{\circ} \mathrm{C}$ and then subjected to 40 cycles of amplification at $95^{\circ} \mathrm{C}$ for $15 \mathrm{~s}$ and $60^{\circ} \mathrm{C}$ for $1 \mathrm{~min}$ for denaturing and annealingextension, respectively. The expression of ADM relative to GAPDH was calculated using a comparative threshold cycle method described in the "User Bulletin \#2" provided by the manufacturer (PE Applied Biosystems) and was determined for each sample.

Enzyme immunoassay of plasma ADM . Enzyme immunoassay (EIA) of ADM was performed using Adrenomedullin Enzyme immunoassay kit (Phoenix Pharmaceuticals, Belmont, CA). Two-hundred microliters of each plasma sample was acidified and extracted with $\mathrm{C} 18$ separation column. Samples were then reacted with primary antibody and biotinylated secondary antibody and reacted subsequently with streptavidin horseradish peroxidase solution. After incubation with substrate solution, the reaction was stopped with $2 \mathrm{~N}$ of $\mathrm{HCl}$ and OD450 was measured in a microplate reader. Because interference of EIA reaction by plasma factor was not eliminated, standard peptides were mixed with plasma from healthy controls and extracted as in the same method as patients' plasma samples, and then standard curve was determined.

Statistical methods. For GeneChip microarray, batch analysis was performed using GeneChip Suite Version 4.0 to assess differences in call (increase, marginal increase, no change, marginal increase, and decrease) and fold change between acute and convalescent samples. Two-tailed paired $t$ test was also done to determine statistically significant differences between acute and convalescent samples after normalized values averaged by intensity of all probes on the array was logarithmically transformed.

RT-PCR of ADM in the PBMCs and plasma ADM concentration were examined with one-factor ANOVA and Scheffe F test as a post hoc test by using the STATVIEW IV program. Real-time PCR of ADM was examined with two-tailed unpaired $t$ test after raw value was logarithmically transformed. Statistically significant difference was set at $p<0.05$.

\section{RESULTS}

In each GeneChip oligonucleotide microarray study, we included an analysis of GAPDH as internal control. We verified the integrity of our RNA by checking the hybridization intensity of the 5', mid-portion, and 3' regions of GAPDH and $\beta$-actin gene. In all samples used in this study, the hybridization intensity of these three portions was similar, indicating that the integrity of the RNA used was intact (data not shown). Next, we focused on genes that demonstrated the greatest differences in hybridization signal intensity between acute and convalescent KD samples.

Table 2 shows the Affymetrix Microarray Suite data analysis results of our KD PBMC samples. "Increase call" represents increased expression of the designated gene in the acute phase of KD compared with the convalescent phase. Of 7129 genes, $>85 \%$ of the genes showed NC (not changed) call in the acute compared with the convalescent phase of KD. Only $0.9-9.5 \%$ of genes showed an increased call in the acute compared with the convalescent phase in each patient pair. Four genes showed increase call in all four patient samples. Forty-three genes showed increase call in three patients. Table 2 shows the results of these 47 genes. Table 3 shows the results of genes that showed a decreased call in the acute compared with the convalescent phase of KD.

Fourteen of the 47 genes in Table 2 showed a statistically significant $(p<0.05)$ increase. The genes with known functions included tumor necrosis factor-stimulated gene-6 (TSG-6), which has anti-inflammatory effects in various models of inflammation (13). This suggests that it is a component of a negative feedback loop that is capable of down-regulating the inflammatory response. Calgranulin B (S-100 protein A9) was significantly increased in acute KD and is known to be a small calcium-binding protein that is highly expressed in the cytosol of neutrophils and monocytes. It is found at high levels in the extracellular milieu during inflammatory conditions, inducing neutrophil chemotaxis and adhesion (14). S-100A12, another S-100 protein family member, has already been reported to be increased in acute-phase KD and is a marker of inflammation (15).

Of greatest interest were genes expressed in immune effector cells that may have vasodilatory effects. These genes are shown in Table 4. A number of genes that are known to be involved in vasodilation did not demonstrate increased expression in the acute compared with the convalescent phase of KD. These gene products include induced nitric oxide synthase involved in the production of nitric oxide (16); prostacyclin synthase, an enzyme involved in production of prostacyclin (17); kininogen, which is known to be converted into bradykinin (18); and tryptophan hydroxylase, which catalyzes the reaction to produce serotonin (19). Importantly, ADM was the only gene that was involved in vasodilation and was significantly $(p=0.024)$ up-regulated in the acute compared with the convalescent phase of KD (20).

To confirm the GeneChip result of ADM, we performed semiquantitative RT-PCR. Figure 1 shows the results of ADM

Table 3. Results of GeneChip microarray: genes with decreased call in at least three patients with acute KD

\begin{tabular}{|c|c|c|c|c|c|c|c|c|c|c|}
\hline \multirow[b]{3}{*}{ Gene name } & \multirow[b]{3}{*}{ Gene accession } & \multicolumn{8}{|c|}{ Patient } & \multirow[b]{3}{*}{ Paired $t$ tes } \\
\hline & & \multicolumn{2}{|c|}{1} & \multicolumn{2}{|c|}{2} & \multicolumn{2}{|c|}{3} & \multicolumn{2}{|c|}{4} & \\
\hline & & $\mathrm{FC}$ & Call & $\mathrm{FC}$ & Call & FC & Call & $\mathrm{FC}$ & Call & \\
\hline $\mathrm{CDC} 25 \mathrm{Hu} 2$ & S78187 & -2.1 & $\mathrm{D}$ & -1.4 & $\mathrm{NC}$ & -1.6 & $\mathrm{D}$ & -3 & $\mathrm{D}$ & \\
\hline Nonerythroid $\alpha$-spectrin & J05243 & -3.2 & $\mathrm{D}$ & -2.2 & $\mathrm{D}$ & -1.7 & $\mathrm{D}$ & -1.4 & $\mathrm{NC}$ & 0.04 \\
\hline Major nuclear matrix protein, matrin 3 & M63483 & -1.8 & $\mathrm{D}$ & -1.9 & $\mathrm{D}$ & -2.1 & $\mathrm{D}$ & -1 & $\mathrm{NC}$ & \\
\hline T-cell receptor active $\alpha$-chain & M12959 & -1.9 & $\mathrm{D}$ & -1.6 & $\mathrm{D}$ & -2.3 & $\mathrm{D}$ & 1.2 & $\mathrm{NC}$ & \\
\hline Perforin gene & M31951 & -7.6 & $\mathrm{D}$ & -6.7 & $\mathrm{D}$ & 1.8 & $\mathrm{I}$ & -3.3 & $\mathrm{D}$ & \\
\hline KIAA0192 & D83783 & -2 & $\mathrm{D}$ & -2.8 & $\mathrm{D}$ & -1.1 & $\mathrm{NC}$ & -2.6 & $\mathrm{D}$ & 0.0498 \\
\hline Src-like kinase & M14676 & -1.6 & $\mathrm{D}$ & -1.5 & $\mathrm{D}$ & -1.4 & $\mathrm{NC}$ & -1.6 & $\mathrm{D}$ & 0.0483 \\
\hline T-cell receptor Ti rearranged $\gamma$-chain mRNA V-J-C region & M30894 & -2.9 & $\mathrm{D}$ & -1.6 & $\mathrm{D}$ & -1.2 & $\mathrm{NC}$ & -2.2 & $\mathrm{D}$ & \\
\hline
\end{tabular}


Table 4. Results of GeneChip microarray of vasoactive genes

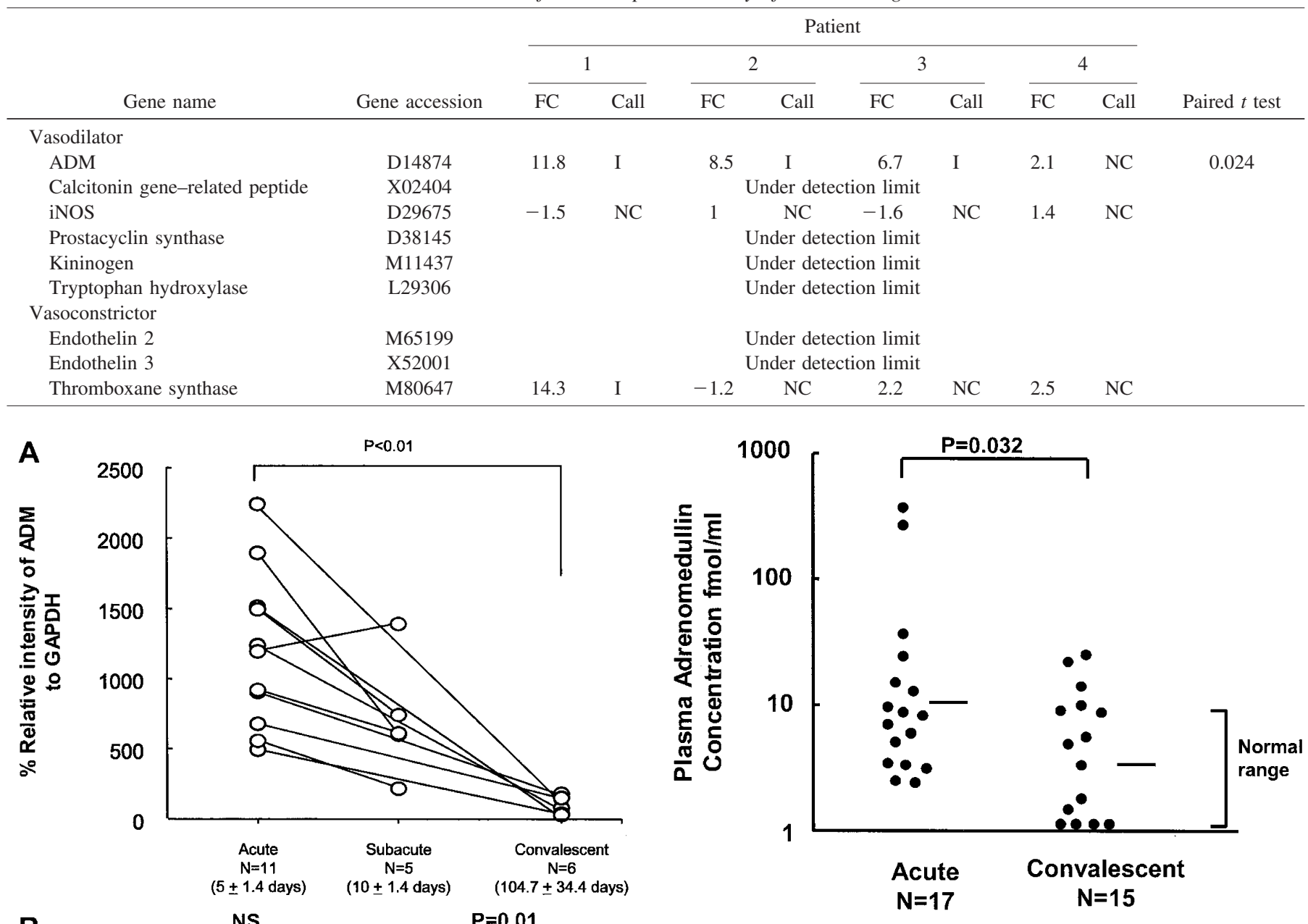

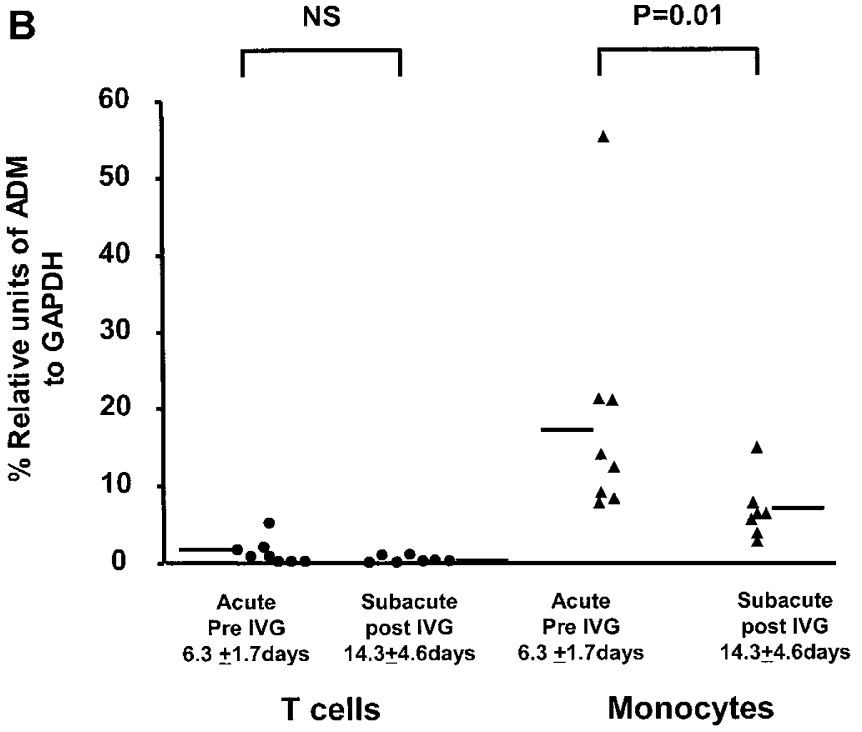

Figure 1. Results of ADM RT-PCR from the RNA of PBMCs from patients with acute and convalescent $\mathrm{KD}$. All results are calculated regarding the densitometric intensity of GAPDH as $100 \%$. From this conventional RT-PCR method, confirming GeneChip microarray result, expression of ADM is high in the acute phase of $\mathrm{KD}$ and diminished in the convalescent phase.

RT-PCR from the RNA of PBMCs in patients with acute and convalescent KD. All results are calculated using the densitometry intensity of GAPDH as $100 \%$. These RT-PCR results confirmed the results from the microarrays.
Figure 2. Monocytes and lymphocytes were separated individually from PBMCs, and real-time PCR of ADM was performed. Monocytes showed higher expression of ADM genes in the acute phase compared with the convalescent phase.

We next determined which cell type in PBMCs was the main producer of ADM. Monocytes and lymphocytes were separated individually from PBMCs, and real-time PCR was performed for the ADM gene. Monocytes but not lymphocytes showed significantly higher expression $(p=0.01)$ of the ADM gene in the acute phase compared with the convalescent phase (Fig. 2). Thus, monocytes seem to be the major producer of ADM mRNA.

EIA results of plasma ADM from KD patients were performed to examine expression of ADM at the protein level. Plasma ADM concentrations of acute-phase patients were significantly $(p=0.032)$ higher than in the convalescent phase. The levels in convalescent KD are similar to levels previously reported in normal controls (21).

\section{DISCUSSION}

Acute $\mathrm{KD}$ is a systemic vasculitis associated with activation of $\mathrm{T}$ cells and macrophages/monocytes in the circulation as well as cardiovascular tissues. A significant proportion of untreated patients with acute KD have coronary artery dilation, and suppression of cardiac contractility is a common finding in 
this illness (3). Immunohistology of autopsy tissues has revealed the infiltration of activated mononuclear cells including macrophages and the up-regulation of adhesion molecules on the vascular endothelium (22). Increased production of macrophage/monocyte-derived cytokines, e.g. tumor necrosis factor- $\alpha$, IL-1, and IL- 6 , have been associated with development of coronary artery disease (23-25).

The current study was carried out to identify novel molecules that could link the activation of immune effector cells with the development of cardiovascular changes in acute KD. A GeneChip oligonucleotide microarray study that screened 7129 genes in PBMCs from four KD patients in both the acute and the convalescent phases of their illness was carried out. Although we have shown all of the data found in this microarray study to stimulate further research in this area, we were primarily interested in molecules with known vasodilatory effects or rate-limiting enzymes to catalyze production of vasodilation molecules. These included ADM (20), induced nitric oxide synthase (16), prostacyclin synthase (17), kininogen (18), and tryptophan hydroxylase (19).

Although PBMCs may not always be the relevant cell type for analysis of disease-relevant genes and the microarray approach may not detect low expression genes, the current studies are still useful in the investigation of prominently upregulated genes. Surprising, ADM was the only vasodilator gene in the microarray study that was found to be increased. This was not a spurious finding because analysis of ADM gene expression by RT-PCR of independent samples of PBMCs from other patients in the acute and convalescent phases of KD also confirmed significantly increased gene expression of $\mathrm{ADM}$ in acute compared with convalescent $\mathrm{KD}$. This was also confirmed at the protein level because plasma concentrations of ADM protein were significantly increased in acute compared with convalescent KD. Our current observation is consistent with another report that plasma ADM protein levels are elevated in acute $\mathrm{KD}$ (26) and confirmed our former presentation (in part) at the Seventh International Kawasaki Disease Symposium that ADM mRNA is highly expressed in PBMCs of acute $\mathrm{KD}(27,28)$.

This is interesting because ADM is known to be a potent vasodilator and therefore may contribute to the dilation of coronary arteries and other middle-sized arteries in acute KD. $\mathrm{ADM}$ is also known to have several other properties that may contribute to the clinical features of acute KD. Recent studies indicate that ADM can cause a significant decrease in contractility of the heart (29). ADM has also been found to induce expression of adhesion molecules, including E-selectin and intracellular adhesion molecule-1, on human vascular endothelial cells (30) and endothelial cell proliferation (31). These actions likely contribute to the vascular inflammation associated with acute KD.

The elevation of plasma ADM, however, cannot completely explain coronary arterial dilation in KD. This is because there are other disease states, such as septic shock (21) and Behçet's disease (32), in which ADM plasma concentrations are elevated but there is no evidence for coronary arterial dilation. Further prospective echocardiography studies are needed to be certain that septic shock and Behçet's disease are not acutely associated with coro- nary artery dilation, however, before we can conclude that ADM does not fully explain coronary artery dilation in acute $\mathrm{KD}$. In our current study, we therefore also examined the potential cell source of ADM in PBMCs. We found that ADM mRNA was highly up-regulated in monocytes/macrophages but not lymphocytes from patients with acute KD. We postulate that these monocytes/ macrophages may infiltrate into the walls of coronary arteries and other blood vessels to deliver ADM to vascular endothelial cells and smooth muscle cells. ADM produced by monocytes/ macrophages therefore may be a potential coronary artery vasodilator in acute KD and reflects a general activation of monocytes/ macrophages in this disease. Future research is needed to examine coronary artery-infiltrating macrophages as a potential source of ADM.

In addition to ADM, a number of other genes were found to be up-regulated in the acute compared with convalescent phase of KD. Several of these genes have known proinflammatory effects, including the nuclear transcription factor c-fos, a member of AP-1 complex that activates the expression of many proinflammatory genes. S-100 A9, a small calcium-binding protein found in the neutrophil and monocyte cytosol, is known to be highly expressed under conditions of inflammation associated with monocyte neutrophil activation. The current study is the first report of the upregulation of S-100 A9 in acute KD. This molecule functions as a neutrophil chemoattractant and therefore may contribute to the infiltration of neutrophils in sites of vasculitis (33). The other calcium-binding protein S100A12 that we found increased causes inflammation through its interaction with the multiligand receptor for advanced glycation end products and has already been reported to be up-regulated in acute KD (34). S-100 A12 enhances monocyte migration (35). It is interesting that TSG-6 was also increased in acute-phase KD. TSG-6, however, has antiinflammatory effects in various models of inflammation (13). This suggests that in addition to the up-regulation of proinflammatory genes, anti-inflammatory proteins are made. Although it was beyond the scope of this study to examine this response in more detail, future studies may be of interest to examine whether patients with persistent fever or tissue inflammation as a result of KD have an inadequate anti-inflammatory response.

\section{CONCLUSION}

In conclusion, the current study has demonstrated an increase of ADM in acute KD. This up-regulation was observed using gene microarray, RT-PCR, and ELISA. Up-regulation of ADM was found by real-time PCR in monocytes but not lymphocytes from patients in the acute phase of KD. These data suggest that ADM produced by monocytes/macrophages that infiltrate the coronary vascular wall may contribute to coronary artery dilation in acute $\mathrm{KD}$.

Acknowledgments. We thank Dr. Jonathan Batchelor for kind correction of English. We thank Maureen Sandoval for assistance in the preparation of this manuscript. We thank Annegret Dunlap for technical assistance in measuring plasma 
ADM. We also thank Aaron Carmody and Todd Woessner for assistance in performing the GeneChip microarray.

\section{REFERENCES}

1. Leung DY, Schlievert PM, Meissner HC 1998 The immunopathogenesis and management of Kawasaki syndrome. Arthritis Rheum 41:1538-1547

2. Fulton DR, Newburger JW 2000 Long-term cardiac sequelae of Kawasaki disease. Curr Rheumatol Rep 2:324-329

3. Kato H, Sugimura T, Akagi T, Sato N, Hashino K, Maeno Y, Kazue T, Eto G, Yamakawa R 1996 Long-term consequences of Kawasaki disease. A 10- to 21-year follow-up study of 594 patients. Circulation 94:1379-1385

4. Koga M, Ishihara T, Takahashi M, Umezawa Y, Furukawa S 1998 Activation of peripheral blood monocytes and macrophages in Kawasaki disease: ultrastructural and immunocytochemical investigation. Pathol Int 48:512-517

5. Hirose S, Hamashima Y 1978 Morphological observations on the vasculitis in the mucocutaneous lymph node syndrome. A skin biopsy study of 27 patients. Eur J Pediatr 129:17-27

6. Leung DY, Giorno RC, Kazemi LV, Flynn PA, Busse JB 1995 Evidence for superantigen involvement in cardiovascular injury due to Kawasaki syndrome. J Immunol 155:5018-5021

7. Lockhart DJ, Dong H, Byrne MC, Follettie MT, Gallo MV, Chee MS, Mittmann M, Wang C, Kobayashi M, Horton H, Brown EL 1996 Expression monitoring by hybridization to $\pi$ high-density oligonucleotide arrays. Nat Biotechnol 14:16751680

8. Yutani C, Okano K, Kamiya T, Oguchi K, Kozuka T, Ota M, Onishi S 1980 Histopathological study on right endomyocardial biopsy of Kawasaki disease. $\mathrm{Br}$ Heart J 43:589-592

9. American Heart Association Committee on Rheumatic Fever, Endocarditis, and Kawasaki Disease 1990 Diagnostic guidelines for Kawasaki disease. Am J Dis Child 144:1218-1219

10. Lee CK, Klopp RG, Weindruch R, Prolla TA 1999 Gene expression profile of aging and its retardation by caloric restriction. Science 285:1390-1393

11. Geraci MW, Moore M, Gesell T, Yeager ME, Alger L, Golpon H, Gao B, Loyd JE, Tuder RM, Voelkel NF 2001 Gene expression patterns in the lungs of patients with primary pulmonary hypertension: a gene microarray analysis. Circ Res $88: 555-562$

12. Lansdorp PM, Aalberse RC, Bos R, Schutter WG, Van Bruggen EF 1986 Cyclic tetramolecular complexes of monoclonal antibodies: a new type of cross-linking reagent. Eur J Immunol 16:679-683

13. Milner CM, Day AJ 2003 TSG-6: a multifunctional protein associated with inflammation. J Cell Sci 116:1863-1873

14. Ryckman C, Vandal K, Rouleau P, Talbot M, Tessier PA 2003 Proinflammatory activities of S100: proteins S100A8, S100A9, and S100A8/A9 induce neutrophil chemotaxis and adhesion. J Immunol 170:3233-3242

15. Foell D, Ichida F, Vogl T, Yu X, Chen R, Miyawaki T, Sorg C, Roth J 2003 S100A12 (EN-RAGE) in monitoring Kawasaki disease. Lancet 361:1270-1272

16. Dawn B, Bolli R 2002 Role of nitric oxide in myocardial preconditioning. Ann NY Acad Sci 962:18-41

17. Venugopal SK, Devaraj S, Jialal I 2003 C-reactive protein decreases prostacyclin release from human aortic endothelial cells. Circulation 108:1676-1678
18. Ito H, Hayashi I, Izumi T, Majima M 2003 Bradykinin inhibits development of myocardial infarction through B2 receptor signalling by increment of regional blood flow around the ischaemic lesions in rats. Br J Pharmacol 138:225-233

19. Ellwood AJ, Curtis MJ 1996 Mechanism of 5-hydroxytryptamine-induced coronary vasodilation assessed by direct detection of nitric oxide production in guinea pig isolated heart. Br J Pharmacol 119:721-729

20. Yoshimoto R, Mitsui-Saito M, Ozaki H, Karaki H 1998 Effects of adrenomedullin and calcitonin gene-related peptide on contractions of the rat aorta and porcine coronary artery. Br J Pharmacol 123:1645-1654

21. Ueda S, Nishio K, Minamino N, Kubo A, Akai Y, Kangawa K, Matsuo H, Fujimura Y, Yoshioka A, Masui K, Doi N, Murao Y, Miyamoto S 1999 Increased plasma levels of adrenomedullin in patients with systemic inflammatory response syndrome. Am J Respir Crit Care Med 160:132-136

22. Brown TJ, Crawford SE, Cornwall ML, Garcia F, Shulman ST, Rowley AH 2001 CD8 T lymphocytes and macrophages infiltrate coronary artery aneurysms in acute Kawasaki disease. J Infect Dis 184:940-943

23. Leung DY, Cotran RS, Kurt-Jones E, Burns JC, Newburger JW, Pober JS 1989 Endothelial cell activation and high interleukin-1 secretion in the pathogenesis of acute Kawasaki disease. Lancet 2:1298-1302

24. Lang BA, Silverman ED, Laxer RM, Lau AS 1989 Spontaneous tumor necrosis factor production in Kawasaki disease. J Pediatr 115:939-943

25. Ueno Y, Takano N, Kanegane H, Yokoi T, Yachie A, Miyawaki T, Taniguchi N 1989 The acute phase nature of interleukin 6: studies in Kawasaki disease and other febrile illnesses. Clin Exp Immunol 76:337-342

26. Nishida K, Watanabe K, Echigo S, Mayumi M, Nishikimi T 2001 Increased plasma adrenomedullin levels in Kawasaki disease with coronary artery involvement. Am J Med 111:165-166

27. Nomura I, Abe J, Saito H, Noma S, Leung DYM 2001 Adrenomedullin mRNA is highly expressed in PBMC of acute Kawasaki Syndrome. The 7th International Kawasaki Disease Symposium; December 4-7, 2001; Hakone, Japan

28. Newburger JW, Taubert KA, Shulman ST, Rowley AH, Gewitz MH, Takahashi M, McCrindle BW 2003 Seventh International Kawasaki Disease Symposium, Hakone, Japan. Pediatr Res 53:153-157

29. Kaygisiz Z, Erksap N, Uyar R, Kabadere S, Kabadere TE, Dernek S 2003 The effect of adrenomedullin, amylin fragment 8-37 and calcitonin gene-related peptide on contractile force, heart rate and coronary perfusion pressure in isolated rat hearts. Acta Physiol Hung 90:133-146

30. Hagi-Pavli E, Farthing PM, Kapas S 2003 Stimulation of adhesion molecule expression in human endothelial cells (HUVEC) by adrenomedullin and corticotrophin. Am J Physiol 286:C239-C246

31. Miyashita K, Itoh H, Sawada N, Fukunaga Y, Sone M, Yamahara K, Yurugi T, Nakao K 2003 Adrenomedullin promotes proliferation and migration of cultured endothelial cells. Hypertens Res 26(suppl):S93-S98

32. Evereklioglu C, Ozbek E, Er H, Cekmen M, Yurekli M 2002 Urinary adrenomedullin levels are increased and correlated with plasma concentrations in patients with Behçet's syndrome. Int J Urol 9:296-303

33. Ryckman C, Vandal K, Rouleau P, Talbot M, Tessier PA 2003 Proinflammatory activities of S100: proteins S100A8, S100A9, and S100A8/A9 induce neutrophil chemotaxis and adhesion. J Immunol 170:3233-3242

34. Foell D, Ichida F, Vogl T, Yu X, Chen R, Miyawaki T, Sorg C, Roth J 2003 S100A12 (EN-RAGE) in monitoring Kawasaki disease. Lancet 361:1270-1272

35. Yang Z, Tao T, Raftery MJ, Youssef P, Di Girolamo N, Geczy CL 2001 Proinflammatory properties of the human S100 protein S100A12. J Leukoc Biol 69:986-994 